\title{
Prediction of Mechanical Behavior of GFRP with Elastomer under Impact and Tensile Loading
}

\author{
Sivaa Charan Muralidharan, Balaji Rajendran
}

\begin{abstract}
In this paper, the mechanical behavior of GFRP laminates reinforced with Elastomers under Impact and Tensile loading conditions has been studied. The GFRP laminates have bidirectional orientation so that it can take loads acting along both $x$ \& y-axis. Composite made of E-glass fibre and Araldite $L Y$ 556 resin was reinforced with Silicone Rubber elastomer. The GFRP laminates were manufactured utilizing the Compression Molding (Sheet Molding) Process. Elastomers are believed to improve the Impact and Tensile Strength of GFRP laminates. Which can be studied only by comparing the Impact and Tensile test results of GFRP with Elastomers to those without Elastomers. A total of ten specimens, five GFRP laminates without Elastomers, and five GFRP laminates with Elastomers were manufactured. For each type, two samples were used to obtain Tensile Strength at $34^{\circ} \mathrm{C} \& 50^{\circ} \mathrm{C}$, and then three specimens were used to gain Impact Strength. The Tensile Strengths were obtained from the Tensile Test as per the ASTM D638 standard of testing, and the Impact Strengths were obtained from the Charpy Impact Test as per the ASTM D256 standard of testing. The specimen dimension for Tensile Test was $4.97 \mathrm{~mm} * 12.9 \mathrm{~mm}$, and the specimen dimension for the Charpy Impact Test was $63.7 \mathrm{~mm}$ * $12.7 \mathrm{~mm}$. The values for Impact Strength and Tensile Strength for each type of specimen were tabulated, utilizing which graphs were plotted between Stress vs. Strain. These values were used to analyze the Mechanical Properties of GFRP with Elastomers under Impact and Tensile Behavior.
\end{abstract}

Keywords: GFRP, Elastomer, Impact Behavior, Tensile Behavior.

\section{INTRODUCTION}

Composite laminates made with Glass Fibre/Epoxy Resin is a ubiquitous material. They are characterized by excellent physical, chemical, thermal, and mechanical properties. According to Jahan et al. [1], Glass fibres possess better physical and mechanical properties when compared to LDPE jute composites, which make them suitable for polymer composites. They are also lower in cost and are readily

Manuscript published on November 30, 2019.

* Correspondence Author

Sivaa Charan Muralidharan*, Department of Aeronautical Engineering, Rajalakshmi Engineering College, Chennai, India. Email: sivaacharan@gmail.com

Balaji Ranjendran, Department of Aeronautical Engineering, Rajalakshmi Engineering College, Chennai, India. Email: rbala04@gmail.com

(C) The Authors. Published by Blue Eyes Intelligence Engineering and Sciences Publication (BEIESP). This is an open access article under the CC-BY-NC-ND license http://creativecommons.org/licenses/by-nc-nd/4.0/

available. According to Mishra et al. [2], bidirectional Jute fibre composites gave better mechanical properties than the unidirectional one. Owing to which Bidirectional GFRP is usually preferred. According to Papa et al. [3], Epoxy resin is the most commonly used, in particular for aerospace applications, because of its excellent resistance to higher temperatures and corrosion and due to its unique mechanical and electrical properties, no styrene emission and more compact failure modes with respect to vinyl ester. But, according to Alagarraja et al. [4], because of the anisotropic nature of composites and the particular subsequent mechanism of damage formation, the impact and tensile performance of fibre-reinforced plastic is often one of the limiting properties during the design. According to Caprino et al. [5], even a low magnitude of impact or load can lead to a severe weakening of the withstanding capacity as a result of delamination caused by the concentrated out-of-plane loads. Nash et al. [6] gave an extensive overview of different methods to improve the impact and post-impact performance of carbon fibre-reinforced composites (CFRP). Good results could be achieved by increasing the overall toughness of the composite, which can be accomplished by the addition of liquid rubber [7]-[8] or thermoplastic particles [9]-[10]. However, Papa et al. [3] found that, although the modification of Epoxy Resin by the addition of liquid rubber improved the mechanical properties of the GFRP laminate, this improvement was not very significant. According to Borggreve et al. [11], the mechanical properties of synthetic rubbers under Impact and Tensile Loading are beneficial for heavy stress applications because rubbers have high elasticity and can absorb a significant amount of energy during high impact loads. Hence, it was suggested that rubbers could be incorporated with Polymers like MMCs and FRPs. According to Das et al. [12], Elastomer based fiber-metal Composites did not have a considerable amount of increase in toughness, but it was able to absorb a significantly high amount of Impact Energy. Therefore, there arose a need to study the mechanical properties of GFRP with a complete layer of rubber. According to O'Connor [13], after reviewing the chemical properties of Short-Fibre Reinforced Elastomer Composites, it was found that the properties of elastomers can be incorporated with FRP with suitable adhesion. Moreover, Hybrid Fibre Reinforced Composites have proved to be very useful in improving the mechanical behavior of FRPs by combining the beneficial mechanical properties of two different materials, [14]-[17]. 


\section{Prediction of Mechanical Behavior of GFRP with Elastomer under Impact and Tensile Loading}

Thus, Epoxy resin of suitable type will be used as the matrix. According to Nicolas et al. [18], the Sheet Compression Molding Process is the most appropriate and commonly used method for the fabrication of FRP in Aerospace applications because of its high accuracy, low wastage, lesser cost, fewer voids, more toughened products, etc.

Wulfsberg et al. [19] showed that Sheet Compression Molding gives the most efficient and productive mechanical properties for CFRP. Ardakani et al. [20] showed that Sheet Compression Molding is the best fabrication method to obtain maximum possible Impact Strength for GFRP laminates. Since our study also deals with attaining maximum potential Impact Strength, we have used Compression Molding Process. Additionally, Kumarasamy et al. [21] found that the overall mechanical failure of GFRP laminates under Impact and Tensile Loading conditions will occur faster with the increase in surrounding temperature and the failure slows down with the decreasing surrounding temperature. Hence, the GFRP with Elastomer will also be mechanically tested under varying temperatures, to study the dependence of the Tensile and Impact Strength of the GFRP with Elastomer on temperature.

\section{EXPERIMENTAL DETAILS}

\section{A. Raw Materials}

Glass Fibre: E-Glass fibre is the type of glass fibre used for this work. It is composed of alumina borosilicate glass with low alkali.The nominal composition of Silicon Dioxide(54\%), Alumina(14\%), Calcium Oxide with Magnesium Oxide(22\%), Boron Trioxide (10\%) \& Sodium Oxide with Potassium Oxide $<2 \%$.

Elastomer: Silicone rubber is an elastomer which is generally non - reactive, stable \& external environment resistant at a temperature from $-55{ }^{\circ} \mathrm{C}$ to $300{ }^{\circ} \mathrm{C}$.

Epoxy Resin: Araldite LY556 is the most common Epoxy Resin used for Aerospace Applications.

Hardener: In the present work, Araldite HY956 is used. It has a viscosity of $10-20$ poise at $250^{\circ} \mathrm{C}$.

Table- I: Raw Material Properties.

\begin{tabular}{|c|c|c|c|c|}
\hline Raw Materials & $\begin{array}{c}\text { Density } \\
\mathbf{( K g . m}^{-3} \text { ) }\end{array}$ & $\begin{array}{c}\text { Young's } \\
\text { modulus } \\
\text { (GPa) }\end{array}$ & $\begin{array}{c}\text { Tensile } \\
\text { strength } \\
\text { (MPa) }\end{array}$ & $\begin{array}{c}\text { Elongation } \\
\mathbf{( \% )}\end{array}$ \\
\hline E-glass Fibre & 2500 & 80 & 2000 & $4.8 \%$ \\
\hline Elastomer & 1.1 & 0.05 & 5.5 & $1100 \%$ \\
\hline Epoxy Resin & 1.2 & 3.4 & 72 & - \\
\hline
\end{tabular}

\section{B. Design of Composites}

GFRP (Glass fibre reinforced polymer) laminate:

Code : $\left[0_{10 \mathrm{~g}}\right]\left(0^{\circ}=90^{\circ}\right.$ in bidirectional $)$

Symmetric : Symmetric about reference axis.

Balance : Balanced structure due to bidirectional ply was used.

GFRP with Elastomer laminate:

Code : $\left[0_{2 g} / 0_{\mathrm{s}} / 0_{2 \mathrm{~g}} / 0_{\mathrm{s}} / 0_{2 \mathrm{~g}}\right]\left(0^{\circ}=90^{\circ}\right.$ in bidirectional $)$

Symmetric : Symmetric about reference axis.

Balance : Balanced structure due to bidirectional ply was used.

\section{Fabrication of GFRP Laminate \\ Sheet/Compression Moulding Process:}

The top and bottom plate temperature was maintained at $80^{\circ} \mathrm{C}$ and pressure was about 10 bar. The raw materials were cut in the required dimension as $30 * 30 \mathrm{~cm}$. The Releasing agent (wax) has been coated on the mica sheet. Over which, Epoxy LY 556 and HY 956 were mixed in the ratio of 10:1, was smeared. Glass fibre was placed on the resin-coated area and then resin added to the surface of glass fibre. Similarly, elastomer was placed and bonded alternatively. In between each layup process, the aluminium rod (cylindrical roller) is rolled on the top layer to reduce voids. Wax coated mica sheet was placed over the surface of the glass fibre laminate before curing, as it serves as a flat surface plate which facilitates proper curing. The curing time was 4 hours.

\section{Testing}

Tensile Test: The Tensile Strength is obtained as per the ASTM D638 standards. The test was conducted for both GFRP with Elastomers and GFRP without Elastomers at $34^{\circ} \mathrm{C}$ and $50^{\circ} \mathrm{C}$ separately. A total of two specimens from each type of material fabricated were used.

Impact Test: The Impact Strength is obtained by the Charpy Impact Test as per the ASTM D256 standards. Three specimens from each type of material fabricated were tested.

Table- II: Test and their corresponding ASTM codes.

\begin{tabular}{|c|c|c|c|}
\hline S. No & Tests & ASTM Codes & Specimen Size (mm) \\
\hline 1. & Tensile Test & ASTM D 638 & $4.97 * 12.97$ \\
\hline 2. & $\begin{array}{c}\text { Impact Test } \\
\text { (Charpy) }\end{array}$ & ASTM D 256 & $63.7 * 12.7$ \\
\hline
\end{tabular}

\section{RESULTS AND DISCUSSIONS}

\section{A. Tensile Test}
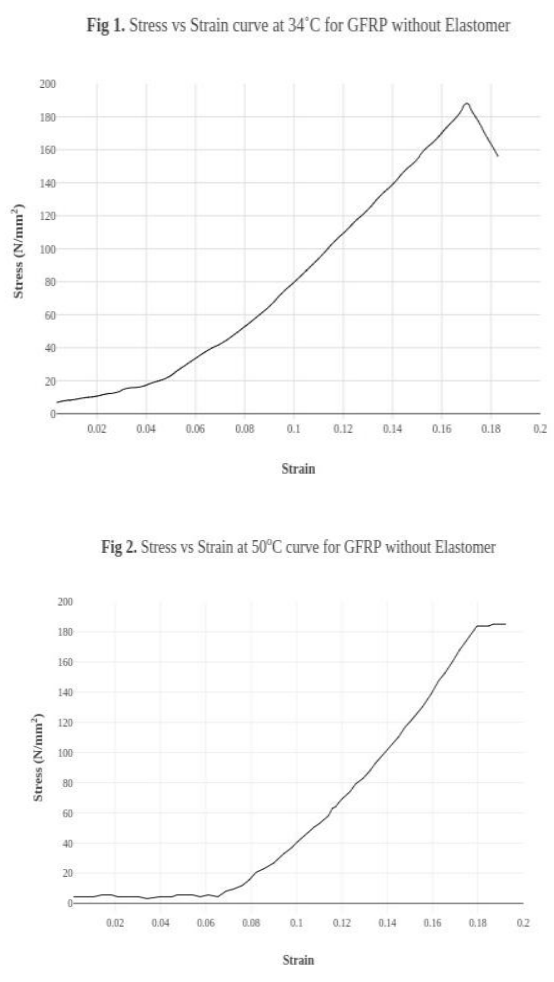
Fig 3. Stress vs Strain curve at $34^{\circ} \mathrm{C}$ for GFRP with Elastomer

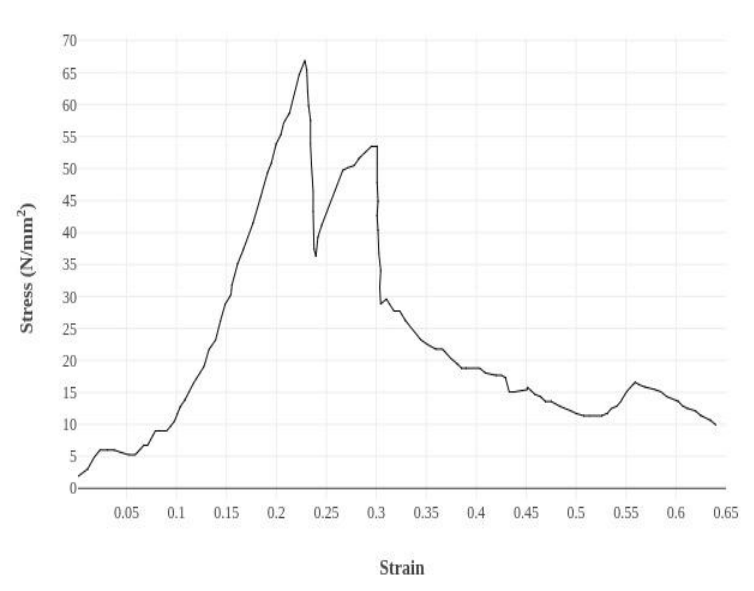

Fig 4. Stress vs Strain curve at $50^{\circ} \mathrm{C}$ for GFRP with Elastomer

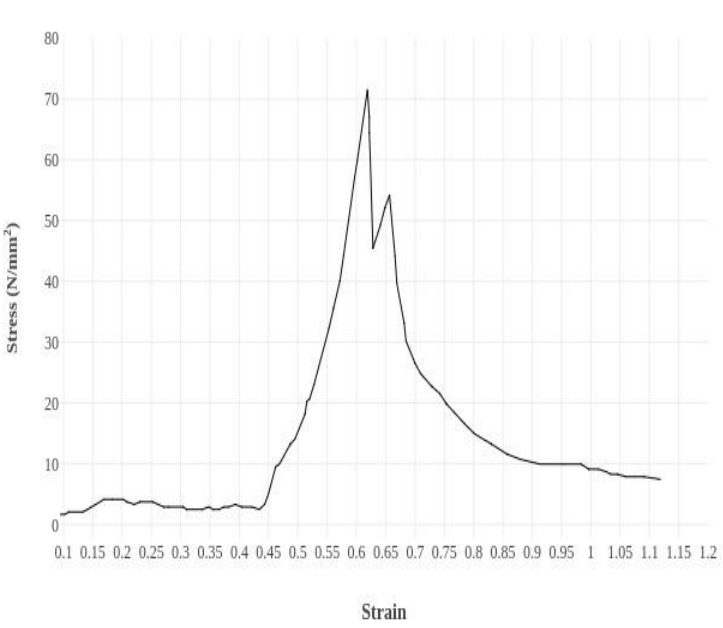

The Stress vs. Strain curves were plotted for both the types of materials fabricated at $34^{\circ} \mathrm{C}$ and $50^{\circ} \mathrm{C}$. For GFRP without Elastomer, the maximum tensile strains were observed as 0.17 at $34^{\circ} \mathrm{C}$ and 0.25 at $50^{\circ} \mathrm{C}$ (From Fig. 1 and Fig. 2). For GFRP with Elastomer, two peaks were observed in the graphs of the specimens at both $34^{\circ} \mathrm{C}$ and $50^{\circ} \mathrm{C}$ (From Fig. 3 and Fig. 4). The overall increase in the maximum tensile strain value due to the presence of Elastomer is 0.3 at $34^{\circ} \mathrm{C}$ and 0.61 at $50^{\circ} \mathrm{C}$ (From Fig. 3 and Fig. 4).

Using the obtained values, it is observed that the tensile strain rate has increased under elevated temperature $\left(50^{\circ} \mathrm{C}\right)$ than at room temperature $\left(34^{\circ} \mathrm{C}\right)$ at maximum applied stress by approximately $50.81 \%$ with Elastomer reinforcements and by $32 \%$ without Elastomer reinforcements.

From the graph, the Maximum Tensile Load to failure $\left(\mathrm{F}_{\max }\right)$ and the Ultimate Tensile Strength (UTS) can also be calculated for each case. The average $F_{\max }$ and average UTS of specimens without Elastomer at both temperatures was approximately found to be $12 \mathrm{kN}$ and $186 \mathrm{MPa}$ respectively. The values of the same, with Elastomer reinforcements was approximately found to be $5.5 \mathrm{kN}$ and $68.5 \mathrm{MPa}$.

\section{B. Charpy Impact Test}

Table- III: Impact Strength of GFRP with Elastomer.

\begin{tabular}{|c|c|c|c|c|c|}
\hline S. & \multirow{2}{*}{ Temp } & \multicolumn{3}{|c|}{ Impact energy (J) } & \multirow{2}{*}{$\begin{array}{c}\text { Average } \\
\text { value }\end{array}$} \\
\cline { 3 - 5 } & $\left({ }^{\circ} \mathrm{C}\right)$ & $\begin{array}{c}\text { Specimen } \\
\mathbf{1}\end{array}$ & $\begin{array}{c}\text { Specimen } \\
\mathbf{2}\end{array}$ & $\begin{array}{c}\text { Specimen } \\
\mathbf{3}\end{array}$ & \\
\hline 1 & 34 & 1.25 & 1.05 & 1.25 & 1.18 \\
\hline 2 & 34 & 1.24 & 1.15 & 1.2 & 1.18 \\
\hline 3 & 50 & 1 & 1 & 1.1 & 1.03 \\
\hline 4 & 50 & 1 & 1.2 & 1.15 & 1.16 \\
\hline
\end{tabular}

Table- IV: Impact Strength of GFRP without Elastomer.

\begin{tabular}{|c|c|c|c|c|c|}
\hline \multirow{2}{*}{$\begin{array}{c}\text { S. } \\
\text { No }\end{array}$} & \multirow{2}{*}{$\begin{array}{l}\text { Temp } \\
\left({ }^{\circ} \mathrm{C}\right)\end{array}$} & \multicolumn{3}{|c|}{ Impact energy (J) } & \multirow{2}{*}{$\begin{array}{l}\text { Average } \\
\text { value }\end{array}$} \\
\hline & & $\begin{array}{c}\text { Specimen } \\
1\end{array}$ & $\begin{array}{c}\text { Specimen } \\
2\end{array}$ & $\begin{array}{c}\text { Specimen } \\
3\end{array}$ & \\
\hline 1 & 34 & 10 & 12 & 10 & 10.6 \\
\hline 2 & $\overline{34}$ & $\overline{10}$ & $\overline{11}$ & $\overline{9}$ & 10 \\
\hline 3 & 34 & 9 & 10 & 9 & 9.3 \\
\hline 4 & 50 & 8 & 12 & 8 & 9.3 \\
\hline 5 & 50 & 9 & 8 & 9 & 8.9 \\
\hline 6 & 50 & 10 & 8 & 10 & 9.3 \\
\hline
\end{tabular}

The average values of Imapct energy can be referred from the above Table- III and Table- IV. The tables evinces that the Impact Energy of the GFRP without Elastomer is higher when compared to the GFRP with Elastomer at both room \& elevated temperature. It can also inferred that in general the Impact Energy is lower in case of elevated temperature $\left(50^{\circ} \mathrm{C}\right)$ tha that of room temperature $\left(34^{\circ} \mathrm{C}\right)$ for both types of specimens.

\section{CONCLUSION}

The Tensile \& Impact test for GFRP without Elastomer shows that it cannot withstand the Tensile \& Impact Load effectively and possess high failure strain rate during tensile tests than normal GFRP (From Fig.1 and Fig. 2). But, the GFRP with Elastomer has two peaks (From Fig. 3 and Fig. 4), which implies that the complete failure of the material due to tensile loads will be delayed and thereby increasing the overall strain rate. The delay in failure of the entire specimen is due to the presence of elastomer reinforcements. The first peak indicates the failure of the outer composiye and the second peak indicates the failure of the inner elastomer reinforcements. This delay maybe advantageous in some cases but still the overall Tensile Strength is not improved. The average values (From Table- III \& Table- IV) show that the Impact Energy of the GFRP without Elastomer is higher when compared to the GFRP with Elastomer at both room \& elevated temperature $\left(50^{\circ} \mathrm{C}\right)$. When impact load is applied on the specimen without Elastomer, the impact is dissipated as impact energy \& at the same time when the load is applied on a specimen with Elastomer there is a slip that is created between the layers and thus the impact load is not dissipated, as in the case of the specimen without Elastomer, due to less availability of friction between the Elastomer \& the Glass Fibre. So, it is advised to make the surface rough so that the layers get adhered properly or use of an Elastomer with rough surface. 


\section{Prediction of Mechanical Behavior of GFRP with Elastomer under Impact and Tensile Loading}

In future, the work can be extended with different loading conditions \& for different orientations of the glass fibre to prove that the stress variation can be improved by the addition of elastomers or other similar natural rubbers.

\section{REFERENCES}

1. Jahan, Arfin \& Rahman, M Mahbubur \& Kabir, Humayun \& Kabir, Md \& Ahmed, Farid \& Hossain, Md.Abul \& Gafur, Md. (2012) Comparative Study of Physical and Elastic Properties of Jute and Glass Fibre Reinforced LDPE Composites. INTERNATIONAL JOURNAL OF SCIENTIFIC \& TECHNOLOGY RESEARCH. 1. 68-72.

2. Mishra, V., \& Biswas, S. (2013). Physical and Mechanical Properties of Bi-directional Jute Fibre Epoxy Composites. Procedia Engineering, 51, 561-566.

3. Papa, I., Ricciardi, M. R., Antonucci, V., Lopresto, V., \& Langella, A. (2016). Impact Performance of GFRP Laminates with Modified Epoxy Resin. Procedia Engineering, 167, 160-167.

4. K. Alagarraja, A. Dhamodharan, K. Gopinathan, R. Mathan Raj, K. Ram Kumar, Fabrication and Testing of Fibre Reinforced Polymer Composite Materials. IOSR Journal of Mechanical and Civil Engineering (IOSR-JMCE) e- ISSN: 2278-1684, p-ISSN: 2320-334X PP 27-34.

5. Caprino, G., \& Lopresto, V. (2000). The significance of indentation in the inspection of carbon fibre-reinforced plastic panels damaged by low-velocity impact. Composites Science and Technology, 60(7), 1003-1012.

6. Nash NH, Young TM, McGrail PT, Stanley WF. Inclusion of a thermoplastic phase to improve impact and post-impact performance of carbon fibre reinforced thermosetting composites - a review. Mater Des 2015; 85:582-97.

7. Hengshi Z, Shiai X. A new method to prepare rubber toughened epoxy with high modulus and high impact strength. Mater Lett 2014; 121:238-40.

8. Nguyen FN, Natsume N, Arai N, Yoshioka K. High performances of core-shell (dendrimer) nanoparticles in carbon fibre/epoxy composites. In: 18th International conference on composite materials (ICCM 18), Korea; 2011.

9. Bull DJ, Spearing SM, Sinclair I, Helfen L. Three-dimensional assessment of low-velocity impact damage in particle toughened composite laminates using micro-focus X-ray computed tomography and synchrotron radiation aluminography. Compos A 2013; 52:62-9.

10. Bull DJ, Scott AE, Spearing SM, Sinclair I. The influence of toughening-particles in CFRPs on low-velocity impact damage resistance performance. Compos A 2014; 58:47-55.

11. Borggreve, R.J.M., Reinoud Jaap Gaymans, and J. Schuijer. Impact behaviour of nylon-rubber blends: 5. Influence of the mechanical properties of the elastomer. (1989).

12. Das, R., S. Rao, and R. J. T. Lin. Impact behaviour of elastomer-based fibre metal laminates. In "Proceedings of the 19th International Conference on Composite Materials (ICCM19). Montreal, Canada". 2013.

13. O’Connor, J. E. (1977). Short-Fibre-Reinforced Elastomer Composites. Rubber Chemistry and Technology, 50(5), 945-958.

14. Meena, V., and Saroya, A., 2011. Study of Mechanical Properties of Hybrid Natural Fibre Composite (Doctoral dissertation).

15. Sanjay, MR and, and B. Yogesha. Studies on mechanical properties of jute/E-glass fibre reinforced epoxy hybrid composites. Journal of minerals and materials characterization and engineering 4, no. 01 , (2016): 15.

16. M. Vasumathi, Vela Murali, Experimental Investigation on the Impact of Presence of Natural Fibre on the Mechanical Performance of a Light Weight Hybrid Bonded Laminate. ISSN: 0975-4024 Vol 6 No 1 Feb-Mar 2014 (IJET).

17. M. Vasumathi, Vela Murali, Effect Of Alternate Metals For Use In Natural Fibre Reinforced Fibre Metal Laminates Under Bending, Impact And Axial Loadings. Procedia Engineering 64 (2013) 562 - 570 Icondm 2013.

18. Nicolas Eguemann, L. Giger, M. Roux, C. Dransfeld, Frédéric Thiebaud, et al. Compression Moulding of complex parts for the aerospace with discontinuous novel and recycled thermoplastic composite materials. 19th International Conference on Composite Materials, Jan 2013, France. pp.1 - 11.

19. Wulfsberg, J., Herrmann, A., Ziegmann, G., Lonsdorfer, G., Stöß, N., \& Fette, M. (2014). Combination of Carbon Fibre Sheet Moulding
Compound and Prepreg Compression Moulding in Aerospace Industry. Procedia Engineering, 81, 1601-1607.

20. Ardakani, Mohammad Alemi, Akbar Afaghi Khatibi, and Seyed Asadollah Ghazavi. A Study on the manufacturing of Glass-Fibre-Reinforced Aluminium Laminates and the effect of interfacial adhesive bonding on the impact behaviour. In Proceedings of the XI International Congress and Exposition. 2008.

21. Kumarasamy, S., Zainol Abidin, M. S., Abu Bakar, M. N., Nazida, M. S., Mustafa, Z., \& Anjang, A. (2018). Effects of High and Low Temperature on the Tensile Strength of Glass Fibre Reinforced Polymer Composites. IOP Conference Series: Materials Science and Engineering, 370, 012021.

\section{AUTHORS PROFILE}

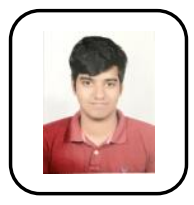

Sivaa Charan Muralidharan, pursuing a Bachelor of Engineering (Aeronautical Engineering) at Department of Aeronautical Engineering, Rajalakshmi Engineering College, Chennai, India, currently doing a project on the Prediction of Failure Pattern in CFRP embedded with SMA Wires using Fracture Approach.

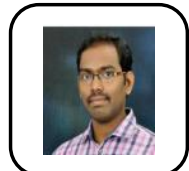

Balaji Rajendran, Assistant Professor (SS) Department of Aeronautical Engineering, Rajalakshmi engineering College, Chennai, India. Currently pursuing $\mathrm{PhD}$ in Madras Institute of Technology, Chennai, India. 